Vol 11, Issue 10, 2018

\title{
THE EFFECT OF DIACEREIN AND MELOXICAM COMBINATION VERSUS MELOXICAM ALONE ON PHYSICAL FUNCTION IN PATIENTS WITH KNEE OSTEOARTHRITIS
}

\author{
NI MADE OKA DWICANDRA*, MADE KRISNA ADI JAYA \\ Department of Pharmacy, Institute of Health Sciences Medika Persada Bali, Denpasar, Bali, Indonesia. \\ Email: okadwicandra@iikmpbali.ac.id
}

Received: 21 May 2018, Revised and Accepted: 21 June 2018

\section{ABSTRACT}

Objective: More than $50 \%$ of patients with knee osteoarthritis (OA) had an inadequate pain relief in its management. Combination therapy could be the solution to this problem. The aim of this study was to compare the efficacy of combination therapy of diacerein and meloxicam with meloxicam alone in the patient with knee OA.

Methods: A total of 64 knee OA patients were recruited from Rumah Sakit Umum Daerah Dr. Mohammad Soewandhie Surabaya. They were allocated to combination group and single therapy group using randomized controlled trial design. The Western Ontario and McMaster Universities Arthritis Index (WOMAC) physical function questionnaire were assessed in weeks $0-4^{\text {th }}$. The difference between pre- and post-treatment score and area under the curve (AUC) of WOMAC score were calculated.

Results: Combination therapy and single therapy had significant clinical effect with the downregulated score of WOMAC physical function after $4^{\text {th }}$ week $(\mathrm{p}<0.05)$. However, there were no differences in AUC of WOMAC physical function score between combination and single therapy.

Conclusion: Patient with knee OA could gain beneficial efficacies from combination therapy of diacerein and meloxicam. Studies of longer follow-up time to get the differences in AUC of WOMAC physical function score are needed.

Keywords: Osteoarthritis, Diacerein, Meloxicam, Western Ontario and McMaster Universities Arthritis Index, Physical function.

(C) 2018 The Authors. Published by Innovare Academic Sciences Pvt Ltd. This is an open access article under the CC BY license (http://creativecommons. org/licenses/by/4. 0/) DOI: http://dx.doi.org/10.22159/ajpcr.2018.v11i10.27427

\section{INTRODUCTION}

Osteoarthritis $(\mathrm{OA})$ of the knee is a major cause of pain and locomotor disability worldwide [1]. Based on the World Health Organization data, $\mathrm{OA}$ is one of the ten most diseases that caused disability in developed countries. In Indonesia, there were $15.5 \%$ men and $12.7 \%$ women between 40 and 60 years who had a radiological knee OA [2].

Muscle weakness, especially of the quadriceps muscle, is one of the major musculoskeletal repercussions of knee OA [3]. As the quadricep muscle acts as a shock absorber in the knee joint, its weakness is believed to reduce functional capacity, predisposing the knee to structural damage [4]. OA and pain symptom experienced by patients have bad effects, such as walking limitations and limitations to work $[5,6]$. However, more than $50 \%$ of patients with knee OA had an inadequate pain relief in its management [7-9].

$\mathrm{OA}$ is a complex process, so the combination of drugs that work by different mechanism may lead to a synergistic effect and can overcome the pain and progression of the disease [10-12]. A combination drug that can be offered to overcome bad physical function of the patient with $\mathrm{OA}$ is diacerein and meloxicam.

Diacerein is an interleukin 1 inhibitor that has efficacy in terms of functional manifestations and structural components of OA [13-15]. It plays an important role in cartilage degradation and stimulation of nociceptive pathways [16]. Diacerein had slow-acting properties, so it must be combined with other analgesics, such as nonsteroidal anti-inflammatory drugs (NSAIDs) to make a faster response in OA therapy $[14,17]$. Meloxicam showed benefit in pain management of knee $\mathrm{OA}$ and had a relatively safe profile. For OA pain therapy, meloxicam should only be used once daily [18-20].
The high prevalence of knee $\mathrm{OA}$ and its impact on the function and quality of life shows the importance of developing strategies for the treatment of that clinical condition. This study aimed at assessing the effect of combination therapy of diacerein and meloxicam and meloxicam alone on the physical function of patients with knee OA. The Western Ontario and McMaster Universities Arthritis Index (WOMAC) score was widely used as a tool to assess the physical function of the patient with arthritis [21,22].

\section{METHODS}

\section{Study design}

We designed an open-label, randomized control trial study. The trial was approved by Badan Koordinasi Pendidikan Rumah Sakit Umum Daerah (RSUD) Dr. Mohammad Soewandhie Surabaya with approval number 070/2554/436.7.8/2016. We used a consecutive sampling method to get participant.

After 5 times of drug elimination half-life of pain medication previously consumed, the patient experienced pain at least $24 \mathrm{~h}$ with scale $\geq 4$ was randomized with blocked randomization method. If patients experienced sudden pain during the washout period, they would be given rescue medication (paracetamol $500 \mathrm{mg}$, maximum $4 \mathrm{~g} /$ day).

Participants received either the combination of diacerein (Artoflam ${ }^{\circledR}$ ) $50 \mathrm{mg}$ once daily and meloxicam $15 \mathrm{mg}$ once daily or meloxicam $15 \mathrm{mg}$ once daily for 4 weeks. Patients were followed up every week. Patients who missed more than $20 \%$ of the drugs were taken out of the study. Other criteria to drop out the participant was incident of severe adverse effect and violation of study protocol.

\section{Patient}

Patients were eligible to participate in the study if they had a knee $\mathrm{OA}$ confirmed by orthopedic spesialist, had radiographic finding consistent 
with the disease, 18-75 years old, body mass index (BMI) $\leq 39 \mathrm{~kg} / \mathrm{m}^{2}$, and had moderate pain when they did not use analgesic (pain score $\geq 4$ with $0-10$ scale). The patient could be included in our study if had a knee OA based on Indonesian Rheumatism Association criteria [2]. Informed consent was obtained from all participants. Patients were recruited from outpatients of the orthopedy clinic in RSUD Dr. Mohammad Soewandhie Surabaya.

Patient with malignancy; pregnant or using hormonal contraceptive; psychiatric disorders using antidepressants, anticonvulsants, antipsychotics, sedatives, or muscle relaxant; drug dependency, drug abuse, or alcohol abuse; hypertension with diastolic $>95$ or systolic $>165$ ), heart failure, or unstable angina; liver and kidney disorder (creatinine clearance $\leq 30 \mathrm{ml} / \mathrm{min}$ that was calculated with CockroftGault formula); bleeding disorder or using anticoagulant or aspirin with daily dose more than $325 \mathrm{mg}$; and history of allergy with drug used in this study were excluded from the study.

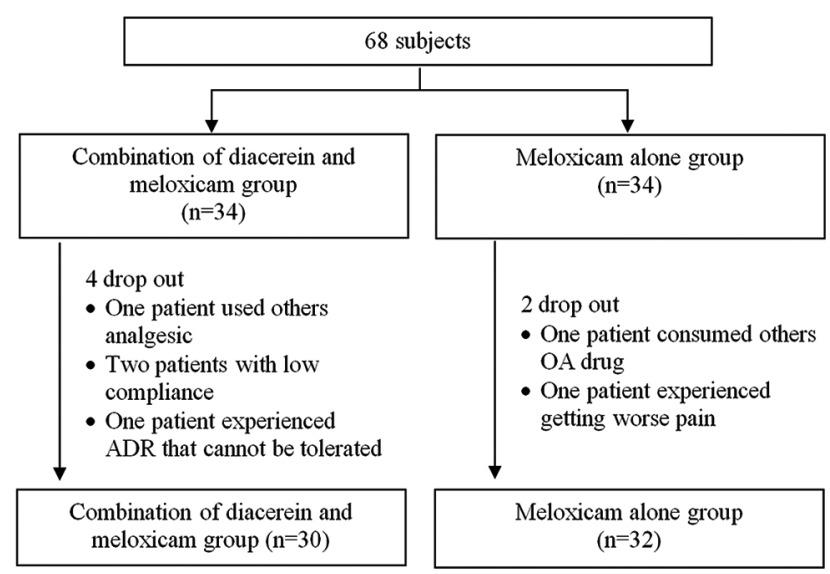

Fig. 1: Participant flow diagram
Evaluation of physical function outcome

Physical function was measured by the WOMAC physical function questionnaire that was translated into Bahasa Indonesia and was validated in our study. The WOMAC physical function score was assessed at baseline and every week until the $4^{\text {th }}$ week. The area under the curve (AUC) of the WOMAC physical function score on each subject was calculated up to 4 weeks of observation using the trapezoidal rule.

\section{Statistical analysis}

The validity of WOMAC physical function test was analyzed with Pearson correlation procedure, and reliability was analyzed with Cronbach's alpha value. Descriptive and inferential statistics were calculated for baseline characteristics. The score of WOMAC physical function was analyzed with per protocol method. Normality of the data was tested with a Shapiro-Wilk test and homogeneity of the data was tested with Levene's test. Paired sample $t$-test or Wilcoxon signed-rank test was used to determine whether pre-treatment and post-treatment groups differed. Independent samples t-test or Mann-Whitney U-test was used to determine the difference between the combination of diacerein and meloxicam and meloxicam alone groups. For all tests, data between different groups were significant if $\mathrm{p}<0.05$.

\section{RESULTS}

A total of 68 subjects were participated (34 subjects per group). Approximately 62 (91.2\%) patients completed the study and included in the analysis (Fig. 1.) The two treatment groups were similar with regard to baseline characteristic (Table 1).

\section{WOMAC physical function evaluation}

The WOMAC physical function score decreased significantly in all groups when compared to the baseline values of each group $(\mathrm{p}<0.05)$ after 4-week therapies (Table 2).

In the $1^{\text {st }}$ week until $3^{\text {rd }}$ week, the difference of WOMAC physical function score between the combination of meloxicam and diacerein and meloxicam alone could not be seen. Those differences were seen

Table 1: Baseline characteristics

\begin{tabular}{|c|c|c|c|c|}
\hline No & Patients characteristics & Combination of diacerein and meloxicam & Meloxicam alone & $\mathbf{p}$ \\
\hline & Gender & & & \\
\hline \multirow[t]{3}{*}{1} & Female $\Sigma(\%)$ & $24(80.0)$ & $25(78.1)$ & 1.000 \\
\hline & Male $\Sigma(\%)$ & $6(20.0)$ & $7(21.9)$ & \\
\hline & Age (years) & & & \\
\hline \multirow[t]{4}{*}{2} & $\geq 60$ & $16(53.3)$ & $18(56.3)$ & 1.000 \\
\hline & $<60$ & $14(46.7)$ & $14(43.8)$ & \\
\hline & Mean \pm SD (year) & $61.13 \pm 8.53$ & $60.41 \pm 7.69$ & 0.860 \\
\hline & BMI & & & \\
\hline \multirow[t]{4}{*}{3} & Normal weight $\Sigma(\%)$ & $11(36.7)$ & $6(18.8)$ & 0.136 \\
\hline & Overweight $\Sigma(\%)$ & $13(43.4)$ & $13(40.6)$ & \\
\hline & Obese $\Sigma(\%)$ & $6(20.0)$ & $13(40.6)$ & \\
\hline & WOMAC physical function score & & & \\
\hline \multirow[t]{2}{*}{4} & Mean $\pm S D$ & $31.70 \pm 11.74$ & $34.34 \pm 10.15$ & 0.346 \\
\hline & Menopausal status & & & \\
\hline \multirow[t]{3}{*}{5} & Menopause $\Sigma(\%)$ & $20(83.3)$ & $24(96.0)$ & 0.189 \\
\hline & Not menopause $\Sigma(\%)$ & $4(16.7)$ & $1(4.0)$ & \\
\hline & OA grade & & & \\
\hline \multirow[t]{5}{*}{6} & $1 \Sigma(\%)$ & $2(6.67)$ & $0(0.0)$ & 0.212 \\
\hline & $2 \Sigma(\%)$ & $8(26.7)$ & $19(59.4)$ & \\
\hline & $3 \Sigma(\%)$ & $16(53.3)$ & $8(25.0)$ & \\
\hline & $4 \Sigma(\%)$ & $4(13.3)$ & 5 (15.6) & \\
\hline & Duration of OA (years) & & & \\
\hline \multirow[t]{4}{*}{7} & $\geq 5 \Sigma(\%)$ & $2(6.7)$ & $1(3.1)$ & 0.607 \\
\hline & $<5 \Sigma(\%)$ & $28(93.3)$ & $31(96.9)$ & \\
\hline & mean \pm SD (years) & $1.13 \pm 1.80$ & $0.75 \pm 1.92$ & 0.089 \\
\hline & Involved joints & & & \\
\hline \multirow[t]{2}{*}{8} & Unilateral & $15(50.0)$ & $12(37.5)$ & 0.462 \\
\hline & Bilateral & $15(50.0)$ & $20(62.5)$ & \\
\hline
\end{tabular}

BMI: Body mass index (normal weight $\geq 18 \mathrm{~kg} / \mathrm{m}^{2}$ and $<25 \mathrm{~kg} / \mathrm{m}^{2}$; overweight $\geq 25 \mathrm{~kg} / \mathrm{m}^{2}$ and $<30 \mathrm{~kg} / \mathrm{m}^{2}$; obese $\geq 30 \mathrm{~kg} / \mathrm{m}^{2}$ ). WOMAC: The Western Ontario and

McMaster Universities Arthritis Index, OA: Osteoarthritis, Sample size: Combination group=30; meloxicam alone group=32 
at $4^{\text {th }}$ week $(\mathrm{p}<0.05)$. There was no significant difference in AUC and improvement of WOMAC physical function score (Table 3).

\section{DISCUSSIONS}

This study showed that a combination of diacerein $(50 \mathrm{mg} /$ day $)$ and meloxicam (15 mg/day) or meloxicam alone (15 mg/day) had a statistically significant analgesic effect (pre- and post-treatment). The effectiveness of meloxicam on the outcome WOMAC physical function score was supported by the randomized controlled trial study by Yocum et al. in the knee and hip OA. It was found that there were differences in WOMAC score of physical function in pre- and post-treatment after 2 weeks of meloxicam (15 mg/day) therapy [18].

In our study, the combination of diacerein and meloxicam was also effective to reduce the WOMAC physical function score after 4 weeks of therapy. There were no studies that compare the combined effects of diacerein and meloxicam. However, there were similar studies conducted by Gupta et al. In the study, diacerein $50 \mathrm{mg}$ administration combined with other NSAID diclofenac $75 \mathrm{mg} / \mathrm{d}(\mathrm{N}=25)$ was shown a significant difference in WOMAC physical function score than baseline score after 12 weeks of therapy. That study did not explain the differences in pain scores over time compared to baseline. That study only compared the differences in WOMAC score in pre and posttreatment [23]. However, the significant WOMAC score reduction after 4 weeks of observation was supported by the results of the literature study, which diacerein effect occurs 2-4 weeks after therapy, and was significant after 4-8 weeks [24]. Meloxicam achieves a significant analgesic effect in 2-4 week [20].

There was a different result of this study and a study conducted by Gupta et al. In our study, the analgesic effect appeared in the $4^{\text {th }}$ week. The difference in the timing of the analgesic effect on the WOMAC score in the literature study and our study may be due to the difference in comparators used. In addition, the differences may also be due to the different follow-up times between our study and the literature.

When we compared with meloxicam alone, the combination of diacerein and meloxicam showed a significant difference in WOMAC physical function score at $4^{\text {th }}$ week. This result indicated that a combination of diacerein and meloxicam was superior to meloxicam alone. In a study conducted by Gupta et al., which compared the combination of diacerein $50 \mathrm{mg} /$ day and diclofenac $75 \mathrm{mg} /$ day with diclofenac $150 \mathrm{mg} /$ day, the WOMAC physical function score difference appeared at $16^{\text {th }}$ week [23].
This result was longer than our study. The differences in the participant characteristic may be responsible for this effect. In another study, meloxicam showed the same effectiveness in overcoming OA pain compared to diclofenac [25].

Pain responses between different participant characteristic may also vary, so participant's factor greatly influences the results of our study. The onset of therapy between Gupta et al. study and this study was different. In Gupta study, the analgesic effect did not appear immediately in early week. Gupta et al. used a different dose of diclofenac in single group and combination group. It may be responsible for delay onset of analgesic effect.

When comparisons were made using the difference and AUC of WOMAC physical function score, the combination of diacerein and meloxicam showed no significant difference. Area under curve data are the result of combining WOMAC score over time calculated using trapezoidal rules. The WOMAC score can be transformed into AUC to access the benefits of analgesia [26]. Compared with measurements at the end of study (EOS), the trial results using AUC provide a smaller treatment estimate but with better precision. The AUC value provides the possibility to maintain the treatment group differences by taking into account the precise onset and offset of drug action. In the COBRA trial with rapid-acting drugs, AUC is more sensitive than EOS to detect treatment differences [27]. The AUC analysis is also more stable and sensitive to interpatient differences than other measures [28]. The AUC describes the cumulative response of an intervention but does not provide information on the onset of analgesic effects. For additional information on the onset of the onset therapy, we used AUC and $1^{\text {st }}-4^{\text {th }}$ week score.

When we compared WOMAC score difference parameters (pre- and post-treatment score) and AUC of WOMAC scores, the combination of diacerein and meloxicam did not show significant differences with meloxicam alone. This suggests that, overall, there was no significant difference in WOMAC outcomes of physical function between diacerein and meloxicam combination groups compared to meloxicam alone. Most studies used the measurement of endpoint study results to see the comparison of therapy outcomes. In a study conducted by Gupta (2012), no comparison of AUC values of WOMAC sore was observed in the combination group diacerein and diclofenac as well as a single diclofenac group [23].

Table 2: Comparison of WOMAC physical function score between pre- and post-treatment in intervention groups

\begin{tabular}{lllll}
\hline No & Groups & WOMAC physical function score & Mean \pm SD & Sig \\
\hline 1 & Combination of diacerein and meloxicam & Pre-treatment & $31.70 \pm 11.74$ & $0.001^{*}$ \\
& & Post-treatment & $17.01 \pm 8.18$ & $34.34 \pm 10.15$ \\
\\
& Meloxicam alone & Pre-treatment & $21.89 \pm 8.90$ & $0.001^{*}$ \\
\hline
\end{tabular}

Sig: Significance, SD: Deviation standard. ${ }^{*} \mathrm{p}<0.05$, Sample size: Combination group=30; Meloxicam alone group=32, WOMAC: The Western Ontario and McMaster Universities Arthritis Index

Table 3: Comparison of WOMAC physical function score between the combination of meloxicam and diacerein and meloxicam alone

\begin{tabular}{|c|c|c|c|c|c|c|}
\hline \multirow[t]{2}{*}{ No } & \multirow[t]{2}{*}{ Time of follow-up } & \multicolumn{2}{|c|}{$\begin{array}{l}\text { Combination of diacerein dan } \\
\text { meloxicam }\end{array}$} & \multicolumn{2}{|c|}{ Meloxicam alone } & \multirow[t]{2}{*}{ Sig } \\
\hline & & Mean \pm SD & CI 95\% & Mean \pm SD & CI 95\% & \\
\hline 1 & Week 0 & $31.70 \pm 11.74$ & $27.32-36.08$ & $34.34 \pm 10.15$ & $30.68-38.00$ & 0.346 \\
\hline 2 & Week 1 & $26.67 \pm 12.13$ & $22.14-31.20$ & $29.72 \pm 9.82$ & $26.18-33.26$ & 0.279 \\
\hline 3 & Week 2 & $24.17 \pm 11.31$ & $19.94-28.39$ & $28.06 \pm 10.08$ & $24.43-31.70$ & 0.157 \\
\hline 4 & Week 3 & $20.67 \pm 9.99$ & $16.93-24.40$ & $24.69 \pm 9.77$ & $21.17-28.21$ & 0.140 \\
\hline 6 & AUC & $95.88 \pm 41.10$ & $80.54-111.23$ & $110.55 \pm 37.60$ & $96.99-124.10$ & 0.148 \\
\hline 7 & Improvement & $14.63 \pm 9.095$ & $11.24-18.03$ & $12.53 \pm 6.76$ & $10.09-14.97$ & 0.577 \\
\hline
\end{tabular}

SD: Standard deviation, CI 95\%: Confident interval 95\%, Sig: Significance, *p<0.05, AUC: Area under curve, Sample size: Combination group=30; meloxicam alone group $=32$ 
The difference in WOMAC physical function data was not used as the main outcome to show the effectiveness of the therapy. It was feared that although at the beginning of the observation there was a decrease in WOMAC physical function score, there was a possibility that the score would again increase to a baseline score or a larger score at the end of the observation. This may cause an unexpected analgesic effect in the midst of observation. The WOMAC physical function score difference showed no significant differences. Hence, it was concluded that, after 4 weeks of therapy, there was no significant improvement in the WOMAC physical function score outcome between the combination and single groups.

Other studies support the non-significant outcome differences in WOMAC physical function scores between the combination of diacerein and meloxicam with meloxicam alone. In our study, the addition of diacerein to meloxicam did not make a significant difference compared to meloxicam alone after 4 weeks of therapy. Meta-analysis and systematic review by Kongtharvonskul et al. showed that diacerein did not clinically significantly reduced the WOMAC function physical (from 8 studies, $\mathrm{p}=0.392$ ) than placebo (follow-up time of $12-16$ week , and doses of 50-100 mg/day) [29].

Another study conducted by Gupta et al. showed a significant difference of WOMAC physical function ( $16^{\text {th }}$ week of follow-up) between the combination of diacerein $50 \mathrm{mg}$ and NSAIDs (Diclofenac $75 \mathrm{mg} /$ day) compared with diclofenac alone. That means we need longer followup to be able to see the difference of WOMAC physical function score between combination effect of diacerein and meloxicam compared to meloxicam alone [29].

Another study conducted by Singh et al. also saw a comparison of the addition of NSAIDs (diclofenac) to diacerein therapy. The study was conducted for 3 month. The combined group $(\mathrm{N}=37)$ used diacerein $50 \mathrm{mg} /$ day in the $1^{\text {st }}$ month, $2 \times 50 \mathrm{mg} /$ day at $2^{\text {nd }}$ and $3^{\text {rd }}$ months, and diclofenac $75 \mathrm{mg} / \mathrm{d}$ sustained release from $1^{\text {st }}$ to $3^{\text {rd }}$ weeks. The comparison group ( $\mathrm{N}=37$ ) only used diclofenac $75 \mathrm{mg}$ /day in sustained release form. The effectiveness of therapy was seen from the total WOMAC score. After 3 months of therapy, the combination group gave a better outcome (WOMAC 15.9 \pm 2.40 ) than diclofenac alone (WOMAC $36.8 \pm 2.92$ ) with a significance value of $\mathrm{p}<0.05$. Thus, for 3 months of therapy, diacerein administration on diclofenac gave a significant difference in WOMAC score compared to diclofenac alone [30]. The above differences also appeared for a longer period ( 3 month) than our study. The study did not explain the difference between WOMAC scores over time, so it is not known when the differences began to appear. If we assumed the differences occurred in the $3^{\text {rd }}$ month ( $12^{\text {th }}$ week), it would take longer observation time from this study to be able to see differences in the effect of diacerein and meloxicam combination compared to single meloxicam in OA patients in WOMAC outcome. In addition, the study used a multilevel dose $(50 \mathrm{mg} /$ day diacerein in the $1^{\text {st }}$ month, followed by $100 \mathrm{mg} /$ day for the next 2 months). These dose differences may also affect the differences in WOMAC outcome.

When referring to the differences in WOMAC score that appears at $4^{\text {th }}$ week, we can said that combination of diacerein and meloxicam was potential to provide benefits in OA therapy. This is also supported by a literature study showing that diacerein effects begin to appear at $2^{\text {nd }}$ and $4^{\text {th }}$ weeks and significant at $4^{\text {th }}$ to $8^{\text {th }}$ week [14]. Thus, intervention up to $8^{\text {th }} \mathrm{w}$ is required to see the differences of AUC of WOMAC physical function score to find the benefits of this combination.

Difference in baseline characteristics can also influence the different results of our study. These factors include gender factors, BMI, duration of $\mathrm{OA}$, education level, and the number of joints with $\mathrm{OA}$. There was a difference in the proportion of men and women in studies conducted by Gupta et al. compared to our study [23]. In our study, sexes were dominated by women (78.1-80.0\%), whereas in studies conducted by Gupta et al., the proportion between sexes of men and women was comparable (male:female $=2: 3$ ). Gender was known affecting WOMAC score. A study conducted by Elboim-Gabyzon et al. in 11 men and 52 women showed that sex can provide significant differences in WOMAC physical function $(\mathrm{p}=0.004)$. Women had WOMAC values greater than men [31]. Research conducted by Elbaz et al using 1487 patient with symptomatic knee OA showed that BMI had a significant relationship with WOMAC physical function $(p<0.001)$ [32]. A study of 105 elderly patients ( $\geq 60$ years) with OA showed that women had worse conditions in WOMAC physical function ( $\mathrm{p}=0.018)$ [33].

However, these studies and Gupta et al. study had a similar BMI category (overweight category), so BMI might not be a factor that made a different outcome.

Duration of OA also had a correlation with WOMAC score or other quality of life parameters. The study by Elstaar (2015), with 116 OA patients, found that patients with a duration of $\mathrm{OA} \geq 5$ years and $<5$ years had a significant difference in the quality of life (p 0.008) [34].

The level of education had a relationship with the WOMAC score. A study conducted by Kulcu et al. on knee OA patients showed that there were inverse correlations of educational level with WOMAC physical function $(r=-0.352 ; p=0.003)$ [35]. The number of joints involved in OA also had a correlation with the WOMAC score. Research by Riddle et al. states that the number of joints involved (unilateral or bilateral) provides significant differences in WOMAC scores, in which bilateral OA scores larger WOMACs [36]. The study by Gupta et al. was not mentioned about duration characteristics, educational level, and the number of joints involved in OA. Therefore, we could not compare Gupta studies with our study [23].

\section{CONCLUSIONS}

The combination of diacerein and meloxicam provided better physical function outcome than meloxicam alone. This significant effect was occurred at $4^{\text {th }}$ week. Longer follows-up time to get the differences in AUC of WOMAC physical function score are needed.

\section{ACKNOWLEDGMENT}

The authors thank all of the subjects for participating in this study. We also acknowledge to orthopedic specialists in the Orthopedic Department of RSUD Dr. Mohammad Soewandhie Surabaya (Dr. Bimo Sasono, Dr. Carlos Supriyantono Binti, Sp.OT, and Dr. Gede Chandra Purnama Yudha, Sp.OT.) that helped the author during data collecting.

\section{AUTHOR'S CONTRIBUTIONS}

Author, Ni Made Oka Dwicandra, made substantial contributions to conception and design, acquisition of data, and analysis and interpretation of data. Co-author, Made Krisna Adi Jaya participated in data collecting, data analyzing, and drafting the article.

\section{CONFLICTS OF INTEREST}

All authors have declared no conflicts of interest.

\section{REFERENCES}

1. Zhang W, Nuki G, Moskowitz RW, Abramson S, Altman RD, Arden NK, et al. OARSI recommendations for the management of hip and knee osteoarthritis: Part III: Changes in evidence following systematic cumulative update of research published through january 2009. Osteoarthritis Cartilage 2010;18:476-99.

2. The Indonesian Rheumatism Association. Diagnosis dan Penatalaksanaan Osteoartritis. Jakarta: The Indonesian Rheumatism Association; 2014.

3. Petterson SC, Barrance P, Buchanan T, Binder-Macleod S, Snyder-Mackler L. Mechanisms underlying quadriceps weakness in knee osteoarthritis. Med Sci Sports Exerc 2008;40:422-7.

4. Fitzgerald GK, Piva SR, Irrgang JJ, Bouzubar F, Starz TW. Quadriceps activation failure as a moderator of the relationship between quadriceps strength and physical function in individuals with knee osteoarthritis. 
Arthritis Rheum 2004;51:40-8.

5. Alldredge BK, Affairs A, Francisco S, Corelli RL, Ernst ME, City I, et al. Koda-Kimble and Young's Applied Therapeutic: The Clinical Use of Drug. $10^{\text {th }}$ ed. Philadelphia, PA: Lippincot Williams and Wilkins; 2013.

6. Łastowiecka E, Bugajska J, Najmiec A, Rell-Bakalarska M, Bownik I, Jedryka-Góral A, et al. Occupational work and quality of life in osteoarthritis patients. Rheumatol Int 2006;27:131-9.

7. Conaghan PG, Peloso PM, Everett SV, Rajagopalan S, Black CM, Mavros $\mathrm{P}$, et al. Inadequate pain relief and large functional loss among patients with knee osteoarthritis: Evidence from a prospective multinational longitudinal study of osteoarthritis real-world therapies. Rheumatology (Oxford) 2015;54:270-7.

8. Jameson K, Balshaw R, Phillips C, Martin GR, Everett SV, Watson DJ, et al. PMS59 inadequate pain relief in knee osteoarthritis and patient reported outcomes: A survey of osteoarthritis real world therapies (SORT) in the United Kingdom. Int Soc Pharm Outcomes Res 2011; 14:A313.

9. Conaghan PG, Peloso PM, Everett SV, Rajagopalan S, Black CM, Mavros $\mathrm{P}$, et al. Inadequate pain relief and large functional loss among patients with knee osteoarthritis: Evidence from a prospective multinational longitudinal study of osteoarthritis real-world therapies. Rheumatology (Oxford) 2015;54:270-7.

10. Mercadante S, Casuccio A, Agnello A, Pumo S, Kargar J, Garofalo S, et al. Analgesic effects of nonsteroidal anti-inflammatory drugs in cancer pain due to somatic or visceral mechanisms. J Pain Symptom Manage 1999; 17:351-6.

11. Frakes EP, Risser RC, Ball TD, Hochberg MC, Wohlreich MM. Duloxetine added to oral nonsteroidal anti-inflammatory drugs for treatment of knee pain due to osteoarthritis: Results of a randomized, double-blind, placebo-controlled trial. Curr Med Res Opin 2011;27:2361-72.

12. Ohtori S, Inoue $\mathrm{G}$, Orita $\mathrm{S}$, Takaso $\mathrm{M}$, Eguchi $\mathrm{Y}$, Ochiai $\mathrm{N}$, et al. Efficacy of combination of meloxicam and pregabalin for pain in knee osteoarthritis. Yonsei Med J 2013;54:1253-8.

13. Fidelix T, Macedo C, Maxwell L, Fernandes Moça Trevisani V. Diacerein for osteoarthritis. Cochrane Database of Systematic Reviews; 2014.

14. Medhi B. Diacerein: A new disease modulating agent in osteoarthritis. Int J Pharm Med Res 2007; 18:48-52.

15. Mahajan A, Singh K, Tandon VR, Kumar S, Kumar H. Diacerein: A new symptomatic slow acting drug for osteoarthritis. JK Sci 2006;8:173-5.

16. Lee AS, Ellman MB, Yan D, Kroin JS, Cole BJ, van Wijnen AJ, et al. A current review of molecular mechanisms regarding osteoarthritis and pain. Gene 2013;527:440-7.

17. Gayathri C, Vanitha S, William FJ, Nirmala P. Comparative analysis of efficacy and safety of diacerein versus S-Adenosyl methionine in the management of osteoarthritis of knee joint. Int J Curr Pharm Res 2017;9:46-51

18. Yocum D, Fleischmann R, Dalgin P, Caldwell J, Hall D, Roszko P, et al. Safety and efficacy of meloxicam in the treatment of osteoarthritis: A 12-week, double-blind, multiple-dose, placebo-controlled trial. The meloxicam osteoarthritis investigators. Arch Intern Med 2000;160:2947-54.

19. Zeidler H, Kaltwasser JP, Leonard JP, Kohlmann T, Sigmund R, Degner F, et al. Prescription and tolerability of meloxicam in day-to-day practice: Postmarketing observational cohort study of 13,307 patients in Germany. J Clin Rheumatol 2002;8:305-15.

20. Tacca MD, Colucci R, Fornai M, Blandizzi C. Efficacy and tolerability of meloxicam, a COX-2 preferential nonsteroidal anti-inflammatory drug. Clin Drug Inves 2002;11:1-22.

21. Bellare N, Harshadargekar, Bhagwat A, Situt V, Pandita N. Effect of a combination of glucosamine and chondroitin sulphate supplementation on the symptomatic relief observed in indian patients with knee osteoarthritis. Int J Pharm Pharm Sci 2013;5:647-50.

22. Patwardhan S, Bodas K, Gundewar S. Coping with arthritis using safer herbal options. Int J Pharm Pharm Sci 2010;2:1-11.

23. Gupta N, Datta S. Efficacy and safety of diacerein and diclofenac in knee osteoarthritis in Indian patients-a prospective randomized open label study. J Biomed Sci 2012;1:1-14.

24. Pelletier JP, Yaron M, Haraoui B, Cohen P, Nahir MA, Choquette D, et al. Efficacy and safety of diacerein in osteoarthritis of the knee: A double-blind, placebo-controlled trial. The diacerein study group. Arthritis Rheum 2000;43:2339-48

25. Goei Thè HS, Lund B, Distel MR, Bluhmki E. A double-blind, randomized trial to compare meloxicam $15 \mathrm{mg}$ with diclofenac $100 \mathrm{mg}$ in the treatment of osteoarthritis of the knee. Osteoarthritis Cartilage 1997;5:283-8

26. Lee CJ, Lee LH, Wu CL, Lee BR, Chen M-L. Clinical Trials of Drug and Biopharmaceuticals. USA: Taylor and Francis Group; 2006.

27. Pham B, Cranney A, Boers M, Verhoeven AC, Wells G, Tugwell P, et al. Validity of area-under-the-curve analysis to summarize effect in rheumatoid arthritis clinical trials. J Rheumatol 1999;26:712-6.

28. Schiff M. A rationale for the use of summary measurements for the assessment of the effects of rheumatoid arthritis therapies. Clin Ther 2003;25:993-1001.

29. Kongtharvonskul J, Anothaisintawee T, McEvoy M, Attia J, Woratanarat P, Thakkinstian A, et al. Efficacy and safety of glucosamine, diacerein, and NSAIDs in osteoarthritis knee: A systematic review and network meta-analysis. Eur J Med Res 2015;20:24.

30. Tonelli SM, Rakel BA, Cooper NA, Angstom WL, Sluka KA. Women with knee osteoarthritis have more pain and poorer function than men, but similar physical activity prior to total knee replacement. Biol Sex Differ 2011;2:12.

31. Elboim-Gabyzon M, Rozen N, Laufer Y. Gender differences in pain perception and functional ability in subjects with knee osteoarthritis. ISRN Orthop 2012;2012:413105

32. Elbaz A, Debbi E, Segal G, Haim A Halperin N, Agar G, Mor A, Debi R. Sex and Body Mass Index Correlate With Western Ontario and McMaster Universities Osteoarthritis Index and Quality of Life Scores in Knee Osteoarthritis. Arch Phys Med Rehabil 2011;92:1618-23.

33. Santos JP, Andraus RA, Pires-oliveira DA, Fernandes MT, Frâncica MC, Poli-frederico RC, et al. Analysis of functional status of elderly with osteoarthritis. Fisioter Pesq 2015;22:161-8.

34. Elstaar TE, Salama AA, Esaily HG, Bolty SA. Quality of life in patients with primary knee osteoarthritis. Menoufi Med J 2015;29:111-4.

35. Kulcu DG, Yanik B, Atalar H, Gulsen G. Associated factors with pain and disability in patients with knee osteoarthritis. Turk J Rheumatol 2010;25:77-81.

36. Riddle DL, Stratford PW. Original article unilateral vs bilateral symptomatic knee osteoarthritis: Associations between pain intensity and function. Rheumatology 2013;52:2229-37. 